\title{
The Influence of Micro - media on the Follow - up Education of College Student Party Members and the Countermeasures
}

\author{
Qihua Wu \\ Jingdezhen Ceramic University, Jingdezhen, Jiangxi 333403
}

\begin{abstract}
The rapid development of the micro-media technology has brought a serious challenge to the current grass-roots party construction work, especially the education and management of college student party members. Only by in-depth study of the features of micro-media in transmitting information, playing the advantages of micro-media, constantly strengthening and improving the grass-roots party construction at colleges and universities, innovating the contents, forms and mechanism of subsequent education and management of party members can we firmly occupy the position of the grass-roots party construction at colleges and universities.
\end{abstract}

Keywords: Micro-media, College students party member, Education and management

\section{微媒体对大学生党员后续教育管理的影响与对策}

\author{
巫奇华 \\ ( 景德镇陶瓷大学 江西景德镇 333403 )
}

摘要: 微媒体技术的迅猛发展给当前高校基层党建工作特别是大学生党员的教育管理带来了严峻的挑战。只有深入研究 微媒体传播信息特点, 发挥微媒体的优势, 不断加强和改进高校基层党建工作, 创新党员后续教育与管理的内容、形式方法 和机制, 才能稳固占领高校基层党建的阵地。

关键词: 微媒体; 大学生党员; 教育管理

中图分类号: G40-058 文摘标识码: A

\section{引言}

随着移动互联网的发展和智能终端设备的应用普及, 我国网民已进入了全新的 “微” 时代。微媒体作 为 “微” 时代最主要的传播媒介, 也是当前网络媒介中的新宠, 正以各种 “微” 传播方式, 如微博、微信、 微小说、微电台、微视频、微课堂等, 在大学生群体中发挥着强大的传播力量, 呈现势不可挡之势, 逐渐 渗入大学生的日常学习、生活和工作之中, 并改变着当代大学生的学习、思维与生活模式, 影响着他们的 政治态度、道德风貌和价值取向和观念, 这势必会对高校大学生党员群体的教育管理工作提出新的挑战。

微媒体作为大学生党员接触现实世界的一种传播媒介, 它们简单便捷、传播性强, 具有高互动性和黏 度性, 只要手指一点, 就能及时的获知想要的内容, 并极大地促进传播和交流的民主化、公开化、个性化, 具有很强的传播性和冲击力。面对微媒体技术的迅猛发展带来的机遇和挑战, 高校党务工作者要深入研究 微媒体传播信息的特点, 积极挖掘微媒体的优势, 不断加强和改进高校基层党建工作, 创新党员教育管理 的内容、形式、方法、手段和机制, 只有这样, 才能占领高校基层党建的新阵地。

\section{1. 微媒体的发展和普及带来的机遇}

传统的大学生党员教育基本停留在党支部 “三会一课” 的会议学习层面上, 缺乏全面性和有效性。在 微技术迅速发展的今天, 微媒体的网络性、即时性和开放互动性, 使人们不受时空的限制, 聚集在一个共 同的虚拟空间里, 以自由的方式表达自己的思想观点、传递信息、交流情感、讨论问题, 甚至参政议政等 等, 为高校党员教育工作提供了前所未有的良好机遇。 


\section{1 微媒体有利于丰富党建内容和形式的多样化}

基于网络的微媒体不同与传统的“纸媒体”，除了文字图片外，它充分发挥网络的声像优势，把枯燥 的党政知识以多形式、多素材、多时空展现出来, 更好地对党组织的先进思想、社会的时事热点、国内国 际的形势与政策问题进行全方位的宣传, 从而引导與论, 有利于实现党建工作内容的丰富化、灵活化, 有 利于大学生开阔视野、提升境界, 从而达到党建工作多样化的目的。因此微媒体的广泛应用使大学生党建 工作突破时空限制, 增强人与人之间交流与沟通, 使得教育的形式更加丰富多样, 教育效果更加显著持久。

\section{2 微媒体有利于促进党建工作交流与互动}

大学生党建工作的关键内容归根到底是做 “人” 的工作, 在传统的思想教育中, 信息接收者往往被比 喻成 “提线木偶”, 入党积极分子的培训和党员后续教育学习往往以被动的灌输方式为主。而在 “微” 时 代下, 微媒体的交互平等性, 把信息发送者和接收者平等对接, 提倡双方彼此尊重理解、互相倾听接纳, 从而促使信息对接流畅, 接收者的诸多需求也得到满足, 在激发大学生党员的社会责任感的同时, 更彰显 了一种人本主义价值观，促进了大学生党员的思想教育管理活动更加顺利有效。

\section{3 微媒体有利于提高学生党员学习的主动性}

微媒体具有大容量、高共享和即时性的优点, 大学生党员可以在各种信息资源共享平台上选择时事资 料、先进思想、名家高见等信息, 及时、迅速、全面地了解时政要闻, 方便系统地查找经典文献。另外, 微媒体为学生党员提供更加广阔的自主学习思考的时间和空间, 他们可以自由利用 “碎片化” 的时间进行 “微” 学习, 自主选择喜欢的文本或其他媒体形式学习, 同时还为学生提供一个表达思想、展示才华的平 台和机会, 进行开创性地学习。

\section{2 微媒体信息传播带来的影响与冲击}

微媒体传播主体的多元化、渠道的开放性、形态的复合式，降低了信息传播的可控性，这种虚拟社会 的状况及其传播特点, 将不可避免地影响到高校学生党员的价值观念和行为方式, 对传统的高校学生党员 的教育管理工作带来了冲击和新的挑战。

\section{1 学生党员的理想信念受到了冲击}

微媒体传播的无界性和自由性已使传统抵御信念风险的“门槛”出现缺口，一些别有用心的国家或极 端性的组织、宗教团体对人的价值及国家利益等方面进行煽动性宣传, 导致不良信息混淆视听, 对大学生 党员的价值取向造成严重干扰。同时网络安全脆弱、垃圾信息泛滥, 以及网络信息的碎片化、娱乐化和可 复制化, 都极大地削弱了大学生的人生理想与道德观念。面对那些宣扬享乐主义、消费主义、现实主义、 金钱至上主义的微媒体信息, 意志薄弱的学生党员感到无所适从, 甚至丧失基本的价值判断力。我们经常 能看到, 有的学生党员僘开主流宣传网站, 迷恋于搜索网上激进的另类观点, 而放弃了对党和理想信念的 追求。

\section{2 “人机交往” 淡化了集体主义意识}

新媒体信息的虚拟性和隐蔽性, 淡化了学生党员的集体主义意识。网络世界的相对自由性和隐蔽性, 往往受尚不成熟的年轻人所向往, 于是 “宅男”、“宅女” 越来越多。在寝室里、课堂上、课余生活里, 越 来越多的学生沉迷于网络游戏和网络交往中, 成为 “人机交往” 的傀儡。受此影响, 一些学生党员也越来 越习惯于 “人机交往”，而不喜欢面对面的过组织生活。这种长期沉迷其中，使人就变成了计算机的一个 
零部件, 从而忽视了自己作为党组织一员的身份, 集体主义意识严重淡化。

\section{3 对党建工作者的综合素质提出了新挑战}

微媒体更新的快速性和开放性, 对高校基层党建工作者的综合素质提出高标准和新挑战。在微时代下, 党建工作者不仅需要丰富的党建工作经验和深厚的党务理论基础, 也需要扎实熟练的新媒体操作技术、开 放现代的交流意识。但是目前很多高校学生党建工作者缺乏理论和微媒体操作技术两方面的综合素质。有 些同志思想政治教育理论功底较为扎实, 对时事热点敏感, 但是教学传播手段还停留在纸媒时代, 不擅长 利用微媒体开展党建工作, 与学生有 “网络代沟”。与此相反的是, 一些新同志擅长使用微媒体技术, 但 缺乏思想政治理论基础和工作经验, 无法做到及时准确的引导学生党员, 更好地传播党性理论和知识。

\section{3. 微媒体环境下学生党建工作的反思与对策}

微媒体相对于报刊、广播、电视等传统媒体而言, 更加及时快捷, 更具时效性和互动性。面对日新月 异的移动互联网和微媒体技术, 高校党建工作者必须站在微媒体技术的前沿, 利用微媒体的交互化、平等 化、个性化等优势, 来弥补传统教育方式的不足, 形成教育合力, 多措并举地提高大学生党员的党性修养 和社会责任感，促进基层党支部的教育管理的实效性。

\section{1 转变 “微” 观念, 抢占党建思想政治和宣传教育的新阵地}

高校基层党建工作者必须站在信息的潮头，具备掌握利用信息的能力。近年来，各高校纷纷建立各类 网站, 各种党建信息资源的开发和利用也有了很大进步, 但其发展尚不尽如人意, 如网站功能单一、信息 量匮乏、缺少寓教于乐的方法和形式等。微媒体已成为高校基层党建工作的新端口, 作为高校党建工作者 要完善高校党建信息网络系统, 开辟独立的信息交流渠道, 大力加强 “两微一端” 新阵地的建设。每天 通过 “两微一端” 定时推送权威资讯、热点聚焦和学习参考内容。把 “两微一端” 着力打造成 “微时代” 的党员必备, 努力使其成为学生党员学习、教育的好助手。同时, 在利用网络信息教育资源时注意提高高 校基层党建工作者的整体素质，增强对网络信息的明辨能力，优化网络教育的内容、形式和方法。

\section{2 搭建 “微” 平台, 提高高校基层党建工作的效率}

利用微媒体的主要功能, 强化微媒体的利用率是高校基层党建工作质量效益的新增长点。因此高校基 层党组织要积极搭建微媒体传播平台, 丰富学生党员教育形式。首先, 充分发挥 “三会一课” 教育的主渠 道作用, 在教学方法上改进, 将微媒体与传统学习方法有机结合, 通过创建微博、微信、微政务等公共平 台, 用新颖生动的典型案例、富有实效的时政评论启发大学生, 将微媒体平台信息内容的学习纳入日常党 员教育考核体系, 以激发大学生利用微媒体学习党政知识、时事热点的动力。其次, 官方微博、微信平台 应集思想性、趣味性、服务性于一体, 将理论学习与现实生活中出现的新情况、新问题, 尤其是将大众反 映强烈的问题结合起来，提高党员教育的实践性。定期更新发布微观点、微公益、微视频，增强大学生党 员对党政知识内容的吸引力。再次, 转变传统说教式为渗透式教育方式, 将党性教育与校园文化、微媒体 融合, 达到隐性熏陶效果, 提高党性教育的实效。

\section{3 培养 “微” 人才, 掌握信息沟通手段的新趋势}

掌握和利用微媒体是高校党建工作者应担负的时代使命, 这也是 “微” 时代对高校党建工作者提出 的新要求。高校基础党建工作者的教育管理对象, 正处在价值观形成的关键时期, 由于心理不成熟、缺乏 社会经验、遇事易情绪化, 对于网络上的一些信息不能完全正确的辨认，很容易受到欺骗和激化。尤其当 
学校面临突发事件时, 学校要利用官方微平台第一时间发布真实信息, 做好正面引导, 满足学生的知情权, 防止学生对信息误判, 禁止事件在传播中升级恶化。因此提高高校基层党组织干部应用、管理新媒体技术 的能力, 提升党性修养和危机事务处理能力, 改善管理干部队伍的结构, 着力培养一批忠诚于党的事业、 热心高校基层党建工作、心系祖国命运、关注国家发展的党建工作新媒体技术人才，是当前高校基层党建 工作的一项迫切任务。

\section{致谢}

基金项目：1、2015 年景德镇市社会科学规划项目： “微” 时代高校基层学生党支部建设新探（项目 编号：2015-11）2、2016 年度江西省党建研究项目: 基于社会责任视角的大学生党员后续教育管理模式创 新研究 (项目编号: 16DJQN036)

\section{Acknowledgement}

Fund Project: 1. 2015 Jingdezhen's Social Science Planning Project: A New Probe into the Construction of Party Branch of Students at the Basic Level in the Era of "Micro" (Project No.: 2015-11) 2. 2016 Jiangxi Provincial Party Construction Research Project: Research on the Innovation Model of College Students' Follow-up Education Management Based on Social Responsibility (Project No.: 16DJQN036)

\section{参考文献:}

[1] 程振凯. 浅谈新媒体环境下的高校学生党建工作 $[\mathrm{J}]$. 华北水利水电学院学报：社科版, 2010 (5): 153-154.

[2] 方敏. 当前高校网络道德教育工作探究 [J]. 学理论, 2011（6): 133.

[3] 鞠斌杰。高校大学生党员后续教育中存在的问题及对策研究 [J]. 中国地质教育, 2015 (6): 40.

[4] 秦艳华, 路英勇. 全媒体时代的手机媒介研究 [M]. 北京: 北京大学出版社, 2013.

\section{作者信息:}

巫奇华 (1978. 01-), 女, 汉族, 福建南平, 硕士，景德镇陶瓷大学，讲师 研究方向: 学生党建和思想政治教育方向

\section{References:}

[1] Cheng Zhenkai. On the Party Construction Work of College Students in the New Media Environment $[\mathrm{J}]$. Journal of North China Institute of Water Conservancy and Hydroelectric Power: Social Science Edition, 2010(5): 153-154.

[2] Fang Min. Research on the Current Network Moral Education in Colleges and Universities [J], Learning Theory, 2011(6): 133.

[3] Ju Binjie. Research on the Problems and Countermeasures of College Students 'Party Members' Follow-up Education [J]. China Geological Education, 2015(6): 40.

[4] Qin Yanhua, Lu Yingyong. Research into Mobile Phone Media in the Era of Omnimedia[M]. Beijing: Peking University Press, 2013. 